\title{
RESISTÊnCIA DE Cyperus difformis a HERBICIDAS INIBIDORES DA ALS EM Lavoura de ARRoZ IRRIgado em SANTA Catarina ${ }^{1}$
}

\author{
Herbicide Resistance of Cyperus difformis to ALS-Inhibitors in Paddy Rice of Santa Catarina
}

\author{
GALON, L. ${ }^{2}$, PANOZZO, L.E. ${ }^{3}$, NOLDIN, J.A. ${ }^{4}$, CONCENÇO, G..$^{2}$, TAROUCO, C.P. ${ }^{3}$, FERREIRA, \\ E.A. ${ }^{2}$, AGOSTINETTO, D. ${ }^{5}$, SILVA, A.A. ${ }^{6}$ e FERREIRA, F.A. ${ }^{6}$
}

\begin{abstract}
RESUMO - A resistência de plantas daninhas a herbicidas tornou-se preocupação mundial nas últimas décadas. Esse fenômeno caracteriza-se pela capacidade de um biótipo de sobreviver a um tratamento com herbicida que controla os demais individuos da mesma população em condições normais de campo e na dose recomendada pelo fabricante na bula. Objetivou-se com este trabalho determinar o nivel de resistência de biótipos de Cyperus difformis a herbicidas inibidores da enzima ALS e do fotossistema II. Os tratamentos foram constituídos pelos herbicidas bispyribac-sodium e pyrazosulfuron-ethyl (inibidores da ALS) e bentazon (inibidor do fotossistema II), aplicados em sete doses múltiplas da dose comercial $(0,0 \mathrm{x}, 0,5 \mathrm{x}, 1 \mathrm{x}, 2 \mathrm{x}, 4 \mathrm{x}, 8 \mathrm{x}$ e $16 \mathrm{x})$, sobre duas populações de plantas de $C$. difformis, quando estas apresentavam de quatro a seis folhas. O biótipo de C. difformis (CYPDI-10) apresentou resistência cruzada aos inibidores da ALS pyrazosulfuron-ethyl e bispyribac-sodium, enquanto o bentazon proporcionou controle eficiente das populações resistente e suscetivel. Conclui-se que para manejo das populações de $C$. difformis resistentes aos inibidores da ALS, em áreas de arroz irrigado de Santa Catarina, devem-se utilizar herbicidas com diferentes mecanismos de ação, associado a outras práticas de manejo, para restringir a expansão das populações resistentes de C. difformis.
\end{abstract}

Palavras-chave: resistência cruzada, pyrazosulfuron-ethyl, bispyribac-sodium, junquinho.

\begin{abstract}
Herbicide resistance is a worldwide phenomenon of great concern to scientists, technicians and producers. It is characterized as the capacity of a biotype to survive a treatment using herbicide that controls the other individuals of the same population under normal field conditions and at the dose recommended by the manufacturer. The objective of this research was to determine the resistance level of two Cyperus difformis biotypes to ALS-inhibiting herbicides. The herbicide treatments consisted of the application of bispyribac-sodium, pyrazosulfuron-ethyl, (ALS-inhibitors) and bentazon (photosystem II inhibitor) sprayed at seven multiple commercial doses $(0,0 x ; 0.5 x ; 1 x ; 2 x ; 4 x ; 8 x$ and $16 x)$, on two plant populations of $\mathbf{C}$. difformis, at the stage of four to six leaves. The CYPDI-10 biotype showed a crossed-resistance to the ALS-inhibiting herbicides pyrazosulfuron-ethyl and bispyribac-sodium, while bentazon showed an efficient control of the resistant and susceptible populations. It was concluded that for the correct management of ALSresistant $\mathbf{C}$. difformis biotypes in flooded rice areas of Santa Catarina, Brazil, the use of herbicides with different action mechanisms should be adopted, as well as other management practices in order to restrict the expansion of resistant populations of $\mathbf{C}$. difformis.
\end{abstract}

Keywords: crossed resistance, pyrazosulfuron-ethyl, bispyribac-sodium, smallflower umbrella sedge.

1 Recebido para publicação em 14.8.2007 e na forma revisada em 27.3.2008.

2 Engo-Agr ${ }^{\circ}$, M.Sc., Doutorando em Fitotecnia, Universidade Federal de Viçosa, Viçosa-MG. 36570-000 < galonleandro@ig.com.br>, bolsista do CNPq-Brasil (autor para correspondência); ${ }^{3}$ Engo-Agro ${ }^{\circ}$, aluno do Programa de Pós-Graduação em Fitossanidade da Universidade Federal de Pelotas - UFPel; ${ }^{4}$ Engo-Agro ${ }^{-}$, Ph.D., Pesquisador da área de Plantas Daninhas da EPAGRI/EEI, Itajaí-SC; ${ }^{5}$ Eng-ํ-Agr ${ }^{\circ}$, Dr., Prof. da Faculdade de Agronomia Eliseu Maciel da UFPel (bolsista CNPq); ${ }^{6}$ Eng - -Agr ${ }^{\circ}$, DS., Prof. do Departamento de Fitotecnia da UFV (Bolsista CNPq).

Planta Daninha, Viçosa-MG, v. 26, n. 2, p. 419-427, 2008 


\section{INTRODUÇÃO}

Algumas espécies de plantas daninhas pertencentes à família Cyperaceae destacamse como invasoras que infestam lavouras de arroz irrigado nos Estados do Rio Grande do Sul e de Santa Catarina, sendo responsáveis pela redução do potencial de produtividade desse cereal. Os efeitos negativos resultantes da presença dessa planta daninha incluem a competição por recursos do meio (luz, água e nutrientes), acamamento das plantas de arroz, dificuldade de colheita, depreciação da qualidade do produto, hospedagem de pragas e doenças, diminuição do valor comercial das áreas cultivadas e aumento dos custos de produção (Kissmann \& Groth, 1997). A espécie Cyperus difformis aparece como uma das que causam prejuízos aos produtores de arroz irrigado. Esta espécie destaca-se pela produção de grande quantidade de sementes (50.000 sementes planta ${ }^{-1}$ ), promovendo rápida infestação da área e também alta taxa de crescimento. Isso tem como conseqüência a formação de grande quantidade de massa verde por área e elevado potencial competitivo com o arroz, especialmente na fase inicial de desenvolvimento da cultura (Kissmann \& Groth, 1997).

O controle das plantas daninhas nas lavouras de arroz pode ser realizado com uso de herbicidas, em razão da praticidade e alta eficiência; contudo, existem dificuldades de controle químico de espécies do gênero Cyperus. Algumas espécies de Cyperus reproduzem-se por sementes e também vegetativamente (tubérculos e estolões), como é o caso de $C$. esculentus e C. rotundus. Além disso, o controle de Cyperus spp. em pré-emergência é especialmente problemático, pela escassez de opções de produtos para controle químico. Para controle em pós-emergência, alguns herbicidas inibidores da enzima acetolactato sintase (ALS), como bispyribac-sodium, penoxsulam, pyrazosulfuron-ethyl, ethoxysulfuron, cyclosulfamuron e azimsulfuron, podem ser aplicados sobre algumas espécies desse gênero, obtendo-se controle satisfatório, respeitandose os estádios de desenvolvimento das plantas no momento da aplicação e o uso dos adjuvantes específicos para cada herbicida (SOSBAI, 2005).

No entanto, o controle de $C$. difformis com herbicidas inibidores da ALS, no Estado de
Santa Catarina, tem apresentado problemas, devido à ocorrência de resistência (Noldin et al., 2002). Os autores relatam que isso decorre principalmente do cultivo intensivo do arroz irrigado adotado nesse Estado, associado ao uso de herbicidas pertencentes a um mesmo mecanismo de ação, por vários anos, favorecendo a seleção de populações resistentes. A resistência de plantas daninhas a herbicidas tornou-se preocupação mundial nas últimas décadas. Esse fenômeno caracteriza-se pela capacidade de um biótipo em sobreviver a um tratamento herbicida que controla os demais indivíduos da mesma população em condições normais de campo e na dose indicada pelo fabricante na bula (Vargas et al., 2007a).

A partir dos anos 80, os inibidores da ALS tornaram-se ferramentas muito importantes para a agricultura; a grande utilização desses produtos deu-se principalmente graças a sua alta eficiência em baixas doses, baixa toxicidade para animais, alta seletividade para algumas culturas e, conseqüentemente, redução do impacto ambiental (Saari et al., 1994). Essas características contribuíram para intensificação do uso desses herbicidas em várias culturas. No entanto, cinco anos após o início do uso desses produtos, começaram a surgir os primeiros casos de plantas daninhas resistentes - atualmente existem 95 espécies resistentes, distribuídas em 34 países (Heap, 2007).

Os primeiros casos de plantas daninhas resistentes a herbicidas em lavouras de arroz irrigado, no Brasil, foram documentados por Noldin et al. (2000, 2002), Eberhardt et al. (2000) e Merotto Jr. et al. (2000), para as espécies Sagitaria montevidensis, Echinochloa crusgalli, E. crus-pavonis e C. difformis.

O grupo HRAC-BR, em sua página na internet, relatou a resistência das espécies Amaranthus spp., Bidens pilosa, $B$. subalternans, Brachiaria plantaginea, Cyperus difformis, Echinochloa crus-galli, E. crus-pavonis, Euphorbia heterophylla, Fimbristylis miliacea e Sagittaria montevidensis aos herbicidas inibidores da ALS, da ACCase e também aos mimetizadores de auxinas. Vargas et al. (2005, 2007 a, b) detectaram a resistência de Lolium multiflorum e de Conyza bonariensis ao herbicida glyphosate em lavouras de culturas perenes (pomares) e anuais (lavouras de soja). 
Em lavouras de arroz da região Sul a resistência de Echinochloa spp. ao herbicida quinclorac está vastamente distribuída, causando transtornos aos orizicultores e aos técnicos envolvidos com o manejo e o controle desta espécie (Andres et al., 2007). Vários trabalhos de pesquisas efetuados no Brasil relataram haver resistência cruzada de plantas daninhas aos herbicidas inibidores da enzima ALS, principalmente dos grupos das sulfoniluréias e imidazolinonas (Gelmini, 2002; Christoffoleti, 2002; Monquero et al., 2000; Grazziero et al., 2006; Pinto et al., 2006), e somente um caso de resistência múltipla a herbicidas inibidores das enzimas ALS e PROTOX, sendo para a espécie de Euphorbia heterophylla (Trezzi et al., 2004).

Há necessidade da explanação de dois conceitos importantes. $\mathrm{O}$ primeiro diz respeito à resistência cruzada, que ocorre quando biótipos de plantas daninhas são resistentes a dois ou mais herbicidas devido a um só mecanismo de resistência, sendo possivel que a planta apresente resistência a todos os herbicidas que apresentam um mesmo mecanismo de ação (Christoffoleti et al., 2004). Os mesmos autores definem como resistência múltipla aquela que ocorre quando um individuo possui um ou mais mecanismos de resistência distintos, que conferem o comportamento resistente a herbicidas com mecanismos de ação diferenciados.

Objetivou-se com este trabalho determinar a resposta de dois biótipos de $C$. difformis, o primeiro com suspeita de resistência a inibidores da ALS (R) e o segundo suscetivel (S) a herbicidas inibidores da enzima ALS e do fotossistema II, visando definir técnicas para manejo desses biótipos em lavouras de arroz.

\section{MATERIAL E MÉTODOS}

O experimento foi conduzido na casa de vegetação do Departamento de Fitossanidade, pertencente à Faculdade de Agronomia Eliseu Maciel, da Universidade Federal de Pelotas (FAEM/UFPel), município de Capão do Leão, RS, no ano agrícola 2006/07.

As sementes de $C$. difformis dos biótipos $\mathrm{R}$ (CYPDI-10) e S (CYPDI-2) aos herbicidas inibidores da ALS foram coletadas no dia 3/4/ 2006, em áreas de lavoura localizadas, respec- tivamente, nos municípios de Meleiro e Capivari de Baixo, no Estado de Santa Catarina.

As unidades experimentais foram representadas por vasos plásticos com capacidade para $400 \mathrm{~mL}$, preenchidos com solo classificado como Planossolo Hidromórfico Eutrófico solódico, pertencente à Unidade de Mapeamento Pelotas (Embrapa, 1999). A adubação foi realizada de acordo com a análise de solo, usandose as recomendações para a cultura do arroz (SOSBAI, 2005). Aos dez dias após a emergência das plântulas, fez-se o desbaste, mantendo-se três plantas por vaso. Os vasos plásticos foram perfurados ao fundo, para que a irrigação das plantas ocorresse por capilaridade, através de água contida em lâmina de aproximadamente $10 \mathrm{~cm}$ de altura, depositada em bandejas plásticas e mantida até a colheita das plantas, para determinação da matéria seca da parte aérea.

O delineamento experimental utilizado foi o inteiramente casualizado, em esquema fatorial $3 \times 7 \times 2$, com quatro repetições por tratamento. O primeiro fator foi composto de dois herbicidas inibidores da ALS [bispyribac-sodium (125 mL ha ${ }^{-1}$ de Nominee $\left.{ }^{\circledR}\right)$ e pyrazosulfuron-ethyl $\left(80 \mathrm{~mL} \mathrm{ha}^{-1}\right.$ de Sirius $\left.\left.{ }^{\circledR}\right)\right]$ e um herbicida inibidor do fotossistema II - bentazon (1,2 L ha $^{-1}$ de Basagran $\left.{ }^{\circledR} 600\right)$; o segundo, por sete doses, múltiplas da dose comercial $(0 \mathrm{x}$, $0,5 \mathrm{x}, 1 \mathrm{x}, 2 \mathrm{x}, 4 \mathrm{x}, 8 \mathrm{x}$ e 16x, sendo $\mathrm{x}$ a dose comercial recomendada para cada produto (SOSBAI, 2005); e o terceiro, por dois biótipos de C. difformis (R e S). Aos herbicidas bispyribacsodium e bentazon adicionaram-se os adjuvantes Ihraguen-S $(0,25 \% \mathrm{v} / \mathrm{v})$ e Assist $\left(1 \mathrm{~L} \mathrm{ha}^{-1}\right)$, respectivamente. Os herbicidas foram aplicados sobre as plantas de $C$. difformis quando estas apresentavam de quatro a seis folhas, em ausência de vento, umidade relativa do ar de $92 \%$ e temperatura de $28{ }^{\circ} \mathrm{C}$, com auxílio de um pulverizador costal pressurizado a $\mathrm{CO}_{2}$ comprimido, munido de um bico de jato plano, tipo leque, modelo XR 110.02, com pressão de trabalho de $250 \mathrm{kPa}$ e barra postada a $40 \mathrm{~cm}$ da superficie do alvo, proporcionando a aplicação de um volume de $150 \mathrm{~L} \mathrm{ha}^{-1}$ de calda herbicida. A irrigação das plantas aspergidas ocorreu dois dias após a aplicação, tempo considerado suficiente para absorção dos herbicidas.

A avaliação de controle das plantas foi feita visualmente, aos 28 dias após aplicação dos 
tratamentos (DAT), utilizando-se escala percentual, em que zero (0) e cem (100) corresponderam à ausência de injúria e morte total das plantas, respectivamente (Burril et al., 1976). Aos 28 DAT, também foi determinada a matéria seca da parte aérea das plantas, coletandoas rente ao solo e levando-as para secar em estufa com circulação forçada de ar a $65^{\circ} \mathrm{C}$, até massa constante, sendo em seguida determinada a matéria seca por planta

Os dados obtidos foram analisados quanto à normalidade e homogeneidade e, posteriormente, submetidos à análise da variância $(\mathrm{p} \leq 0,05)$; quando significativos, foi realizada a análise de regressão de modo a obter a dose que exerça $50 \%$ de controle $\left(\mathrm{LD}_{50}\right)$ e que reduza $50 \%$ do crescimento $\left(\mathrm{GR}_{50}\right)$, utilizando o software SigmaPlot 8.02 (1999), ajustando-se ao modelo da hipérbole retangular de dose-resposta, representado pela equação 1 para níveis de controle e pela equação 2 para acúmulo de massa seca aérea:

$$
\begin{aligned}
& \text { Equação 1: } Y=\frac{\mathrm{a} \cdot \mathrm{X}}{\mathrm{b}+\mathrm{X}} \\
& \text { Equação 2: } \mathrm{Y}=\frac{\mathrm{a} \cdot \mathrm{b}}{\mathrm{b}+\mathrm{X}}
\end{aligned}
$$

em que $Y$ representa o controle ou matéria seca da parte aérea de $C$. difformis; $X$, a dose comercial do herbicida; $b$, o coeficiente de declividade; e $a$, a assíntota máxima.

\section{RESULTADOS E DISCUSSÃO}

O bentazon controlou com eficiência tanto o biótipo de $C$. difformis com suspeita de resistência a herbicidas inibidores da ALS (R) quanto o suscetivel (S), a partir da dose de $0,5 \mathrm{x}$ da dose comercial (Figura 1A). Segundo Coutinho et al. (2005), o bentazon apresenta risco médio para o desenvolvimento de resistência. Pode ser ótima alternativa para controle de espécies daninhas de folhas largas e ciperáceas resistentes aos inibidores da ALS (Noldin \& Eberhardt, 2001; Concenço et al., 2007a). No entanto, já foram registrados no Brasil, no Estado do Paraná e em lavouras de milho, dois casos de plantas daninhas resistentes aos herbicidas que têm ação no fotossistema II: caruru (Amaranthus spp.) (HRAC/BR, 2000) e, recentemente, picão-preto (Bidens sp.) (Gazziero et al., 2007), ao grupo químico das triazinas, mesmo mecanismo de ação do herbicida bentazon.
Quanto aos inibidores da ALS, o pyrazosulfuron-ethyl controlou com eficiência plantas do biótipo $\mathrm{S}$ a partir da dose $1 \mathrm{x}$ (Figura 1B). No entanto, o biótipo $R$ não foi controlado de maneira eficaz mesmo com uso de $16 \mathrm{x}$ a dose comercial do herbicida. Apesar de a eficiência de controle do biótipo $\mathrm{R}$ ter aumentado com a elevação da dose entre 0 e $2 x$, houve tendência de estabilização dos níveis de controle ao redor de $50 \%$ entre os niveis de $2 \mathrm{x}$ a $16 \mathrm{x}$ de pyrazosulfuron-ethyl. O bispyribac-sodium proporcionou controle satisfatório do biótipo $\mathrm{S}$ (maior que $80 \%$ ) a partir da dose $1 \mathrm{x}$, alcançando $100 \%$ de controle com doses superiores a $2 \mathrm{x}$ (Figura 1C). No entanto, para o biótipo R, a dose de $1 \mathrm{x}$ controlou somente $60 \%$ das plantas, atingindo $80 \%$ de controle com a dose máxima aplicada (16x). Esses resultados estão de acordo com Vidal (2002), o qual afirma que, a princípio, herbicidas que apresentam mecanismos de ação semelhantes tendem a expressar eficácia análoga no controle de plantas daninhas. Isso, contudo, não é regra geral, já que pequenas diferenças nos grupos químicos ou nos sítios de atuação podem produzir resultados diferentes. Kissmann (2000) afirma que um biótipo resistente a um inibidor de ALS também pode ser menos resistente ou suscetivel a outro produto do mesmo mecanismo de ação. Além disso, o mesmo biótipo resistente normalmente apresenta niveis de resistência distintos a herbicidas de igual mecanismo de ação (Gelmini et al., 2002; Vargas et al., 2007a e b; Gazziero et al., 2006).

$\mathrm{A} \mathrm{DL}_{50}$ de bentazon - dose necessária para efetivamente eliminar 50\% das plantas de determinado biótipo (Neve \& Powles, 2005) - foi inferior a $50 \%$ da dose recomendada, tanto para o biótipo resistente como para o suscetivel aos inibidores da ALS (Figura 1D). No entanto, a $\mathrm{DL}_{50}$ de pyrazosulfuron-ethyl para o biótipo $\mathrm{S}$ foi inferior a $25 \%$ da dose comercial, demonstrando sua elevada eficácia para esse biótipo, enquanto para o biótipo $\mathrm{R}$ foi necessário mais de $600 \%$ da dose comercial. $\mathrm{A} \mathrm{DL}_{50}$ de bispyribac-sodium para o biótipo S, por sua vez, equivaleu a $30 \%$ da dose comercial, enquanto para o R atingiu valor próximo ao da dose recomendada (Figura 1D).

A matéria seca da parte aérea de ambos os biótipos mostrou comportamento similar em função de doses de bentazon, sendo 
A
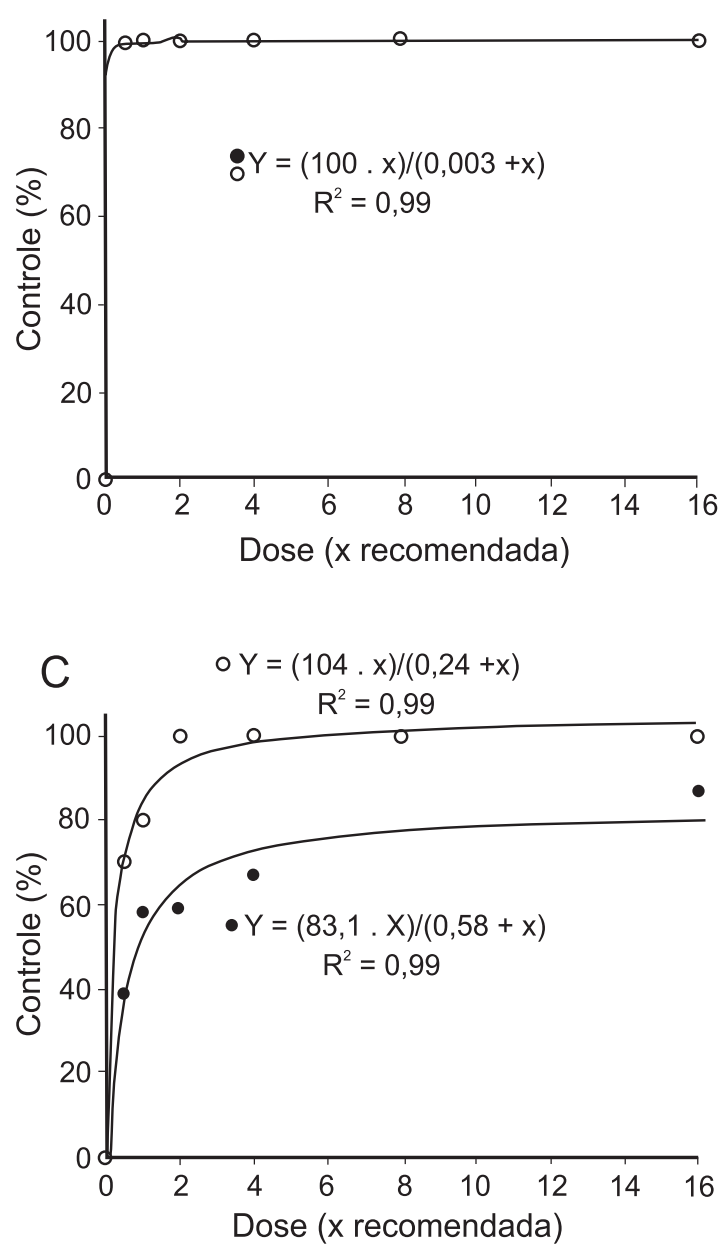

B
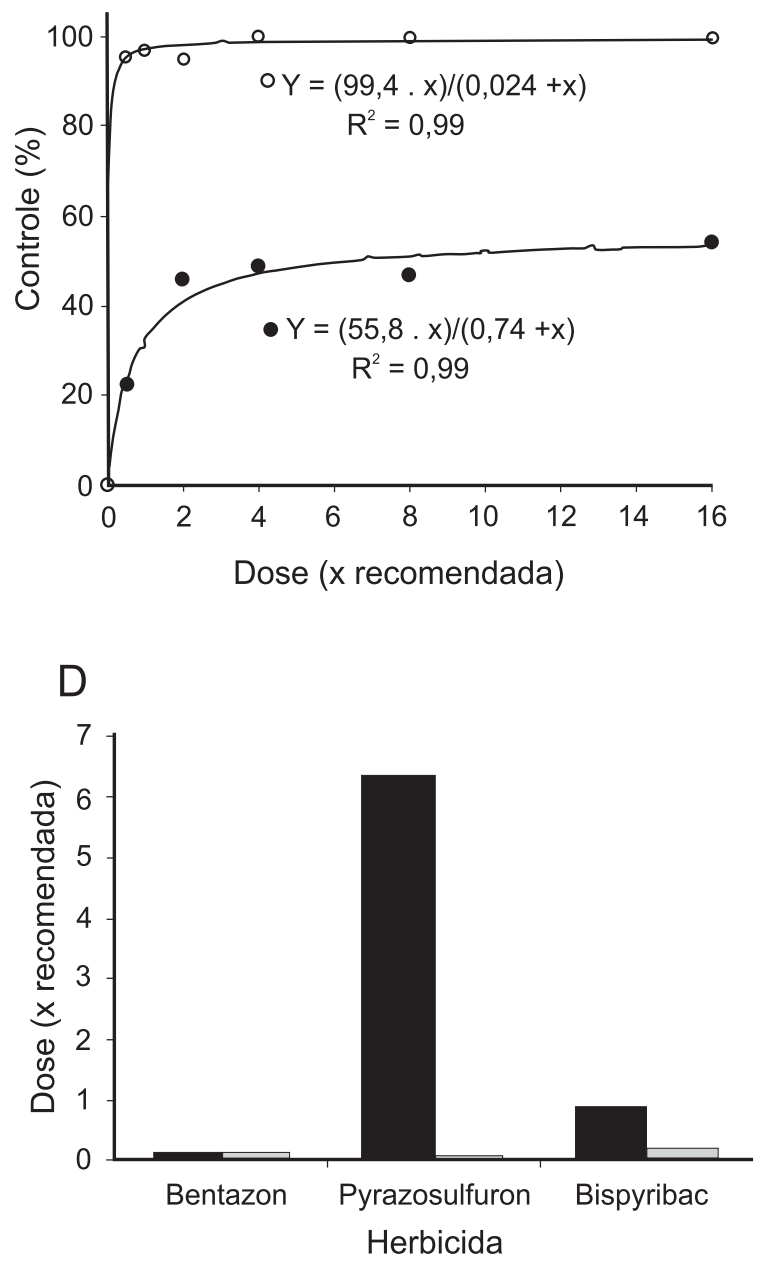

Figura 1 - Controle (\%) dos biótipos de Cyperus difformis resistentes $(\bullet)$ e suscetível (O) proporcionado pelos herbicidas inibidores do fotossistema II e da ALS em função de doses: bentazon (A), pyrazosulfuron-ethyl (B), bispyribac-sodium (C) e (D) dose dos

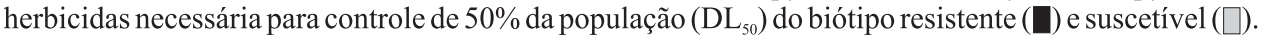

representados pela mesma equação (Figura 2A). A redução no acúmulo de matéria seca aérea foi de 85 e $80 \%$ para os biótipos R e S, respectivamente, ao se comparar a dose de $0,5 \mathrm{x}$ com o tratamento sem aplicação. Mesmo nas maiores doses de bentazon, em que ocorreu morte das plantas, ainda havia matéria seca das partes aéreas nas unidades experimentais, em razão de algumas plantas necessitarem de mais tempo para obtenção de controle eficaz.

Para o biótipo S, o pyrazosulfuron-ethyl e na dose correspondente a $4 \mathrm{x}$ a recomendada permitiu o acúmulo de matéria seca da parte aérea ao redor de $20 \%$, em relação ao observado no tratamento sem herbicida (Figura 1B).
Por outro lado, o biótipo R não apresentou resposta ao aumento na dose de pyrazosulfuronethyl, entre 0 e $16 x$.

Quanto ao bispyribac-sodium, este permitiu acúmulo de matéria seca da parte aérea ao redor de $50 \%$ do observado no tratamento sem herbicida para ambos os biótipos, a partir de $0,5 \mathrm{x}$ a dose recomendada. No entanto, a diferença numérica foi maior no $\mathrm{S}$, que apresentou no tratamento sem herbicida maior matéria seca da parte aérea que o $\mathrm{R}$ (Figura 2C). Somente a partir da dose de $8 \mathrm{x}$ o biótipo $\mathrm{R}$ apresentou matéria seca da parte aérea próxima à observada no $\mathrm{S}$ - em torno de $10 \%$ do observado no tratamento sem aplicação. Se 
forem relativizadas as matérias secas das testemunhas sem herbicida em cada biótipo para o valor 100 , os valores de matéria seca dos biótipos se aproximarão, o que mostrará que as diferenças entre os biótipos é pequena ou quase nula para esse herbicida. De modo semelhante ao percentual de controle, o bispyribac-sodium causou maior redução no acúmulo de matéria seca da parte aérea de plantas no biótipo R que o pyrazosulfuron-ethyl, o que refletiu em maiores valores de $\mathrm{GR}_{50} \mathrm{e}$ $\mathrm{DL}_{50}$ para o segundo (Figura 2D). Além disso, é importante salientar que, em todos os tratamentos sem herbicidas, as plantas do biótipo $\mathrm{S}$ apresentaram maior acúmulo de matéria seca da parte aérea que plantas do biótipo R. Seria interessante investigar, em futuros estudos, se estes biótipos diferem quanto à adaptabilidade ambiental, da mesma forma que $L$. multiflorum resistente e suscetivel ao glyphosate (Concenço et al., 2007b; Ferreira et al., 2008), em que o biótipo resistente possui menor adaptabilidade ecológica que o suscetivel. Corroborando com os resultados desses autores, Vargas et al. (2007a) também detectaram maior adaptabilidade do biótipo de buva resistente ao herbicida glyphosate, em comparação com o biótipo suscetivel.

$\mathrm{O}$ bentazon foi muito eficiente em reduzir o crescimento e acúmulo de massa nas plantas de C. difformis resistentes e suscetiveis aos inibidores da ALS (Figura 2D). A dose de bentazon necessária para reduzir em $50 \%$ o crescimento das plantas de ambos os biótipos ficou próxima a $10 \%$ da recomendada. O pyrazosulfuron-ethyl, por outro lado, necessitou em torno de $30 \%$ da dose recomendada para reduzir em $50 \%$ o crescimento do biótipo S; entretanto, não reduziu eficientemente o acúmulo de matéria seca aérea em plantas do biótipo $\mathrm{R}$ até a maior dose avaliada, ou seja, a $\mathrm{GR}_{50}$ de pyrazosulfuron-ethyl aplicado sobre plantas do biótipo $\mathrm{R}$ é superior a $1.600 \%$ da dose recomendada, pois não se encontrou no intervalo avaliado (Figura 2D).

O bispyribac-sodium reduziu em $50 \%$ o acúmulo de matéria seca da parte aérea do biótipo S com dose ao redor de 30\% a recomendada, com resposta muito similar à observada para pyrazosulfuron-ethyl (Figura 2D). Por outro lado, o biótipo $R$ atingiu a $\mathrm{GR}_{50}$ com doses em torno de $220 \%$ a dose recomendada, sendo muito menor que o observado para pyrazosulfuron-ethyl.

Observou-se ainda que os herbicidas pyrazosulfuron-ethyl (Figura 1B) e bispyribac-sodium (Figura 1C) apresentaram niveis de controle próximos a $100 \%$ para o biótipo de C. difformis suscetivel e inferior a $70 \%$ para o resistente. Quanto à variável matéria seca da parte aérea, a mesma tendência foi observada, ou seja, o biótipo suscetivel apresentou menor quantidade de matéria seca acumulada, sendo superior ao resistente. Este herbicida demonstrou ser mais eficiente que o bispyribac-sodium na redução da primeira variável e menos eficiente na segunda. No entanto, para o herbicida bentazon, não se observaram diferenças no controle (Figura 1A) para os dois biótipos testados, nem mesmo para a variável matéria seca da parte aérea (Figura 2A). Pode-se inferir que neste experimento houve reduzida eficiência dos herbicidas cujo mecanismo de ação é a inibição da enzima ALS (pyrazosulfuron-ethyl e bispyribac-sodium) e alta eficácia ao se alternar o mecanismo de ação dos herbicidas para inibidores do fotossistema II (bentazon), percebendo-se que há resistência cruzada entre os herbicidas inibidores da ALS, não sendo observada resistência a mais de um mecanismo de ação herbicida. Pesquisas relatam a ocorrência de resistência cruzada aos herbicidas inibidores da ALS (Gazziero et al., 1998; Vidal \& Merotto Jr., 1999; Monquero et al., 2000; Gazziero et al., 2006; Pinto et al., 2006) e que o surgimento de biótipos resistentes a estes herbicidas deve-se, em grande parte, à utilização intensiva e contínua, em uma mesma área, de herbicidas com um único sítio de ação (Tranel \& Wright, 2002).

Diante dos resultados expostos, concluise que o biótipo CYPDI-10 de C. difformis apresenta alto nivel de resistência ao herbicida pyrazosulfuron-ethyl e resistência cruzada com o herbicida bispyribac-sodium, respectivamente dos grupos químicos sulfoniluréia e pirimidinyl thiobenzoato, inibidores da enzima ALS. O bentazon apresenta-se como alternativa eficiente para controle químico do biótipo de $C$. difformis resistente. No entanto, destaca-se que, para manejo de populações de C. difformis resistentes aos herbicidas inibidores da ALS nas áreas de arroz irrigado em Santa Catarina, além disso, é recomendável 

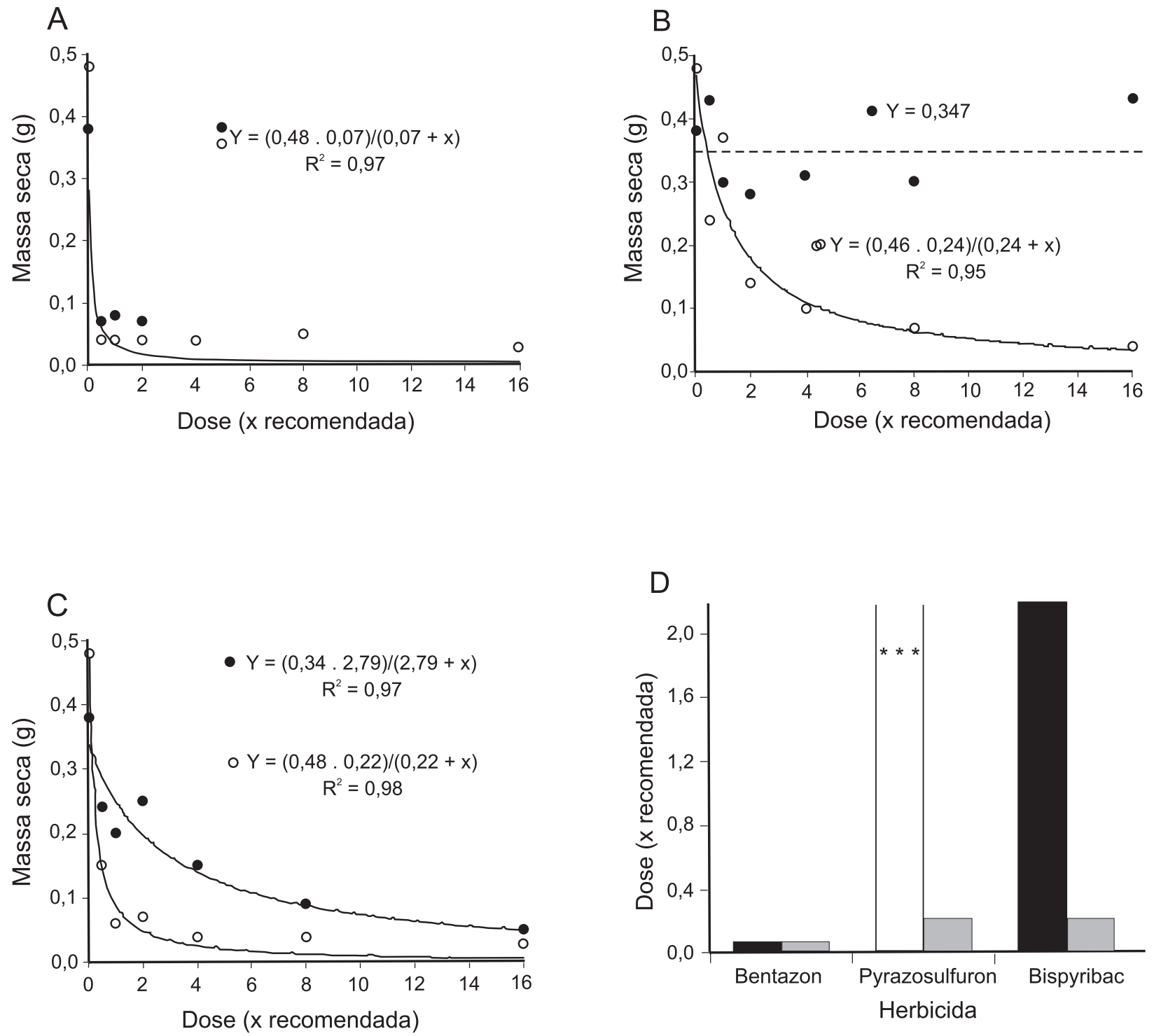

Figura 2 - Matéria seca da parte aérea por planta (g) dos biótipos de Cyperus difformis resistente (• ) e suscetível (O) tratada com herbicidas inibidores do fotossistema II e da ALS em função de doses: bentazon (A), pyrazosulfuron (B), bispyribac-sodium (C) e (D) dose dos herbicidas necessária para reduzir em $50 \%$ o crescimento das plantas $\left(\mathrm{GR}_{50}\right)$ do biótipo resistente ( $($ ) e suscetível ( $\square$ ). ${ }^{* * *} \mathrm{GR}_{50}$ superior ao intervalo avaliado.

a adoção de práticas como a rotação de herbicidas com diferentes mecanismos de ação e de práticas de manejo que possam restringir a expansão das populações resistentes.

\section{AGRADECIMENTOS}

Os autores agradecem ao Conselho Nacional de Desenvolvimento Científico e Tecnológico (CNPq-Brasil) a concessão de bolsas.

\section{LITERATURA CITADA}

ASSOCIAÇÃO BRASILEIRA DE AÇÃO A RESISTÊNCIA DE PLANTAS AOS HERBICIDAS - HRAC-BR.

Disponível em: (http://www.hrac-br.com.br). Acesso em: 3 de julho de 2007.

ANDRES, A. et al. Detecção da resistência de capim-arroz (Echinochloa sp.) ao herbicida quinclorac em regiões orizícolas do sul do Brasil. Planta Daninha, v. 25, n. 1, p. 221-226, 2007. 
BURRILL, L. C.; CARDENAS, J. C.; LOCATELLI, E. Field manual for weed control research. Corvallis: International Plant Protection Center, Oregon State University, 1976. 59 p

CHRISTOFFOLETI, P. J. Curvas de dose-resposta de biótipos resistente e suscetível de Bidens pilosa L. aos herbicidas inibidores da ALS. Sci. Agríc., v. 59, n. 3, p. 513519, 2002.

CHRISTOFFOLETI, P. J.; LOPEZ-OVEJERO, R. F.; CARVALHO, J. C. Aspectos de resistência de plantas daninhas a herbicidas. 2. ed. Campinas: Associação Brasileira de Ação a Resistência de Plantas a Herbicidas (HRAC-BR), 2004. 100 p

CONCENÇO, G. et al. Aspectos da resistência de Sagittaria montevidensis ao herbicida pirazosulfuron-ethyl inibidor da ALS. Planta Daninha, v. 25, n. 1, p.187-194, 2007a.

CONCENÇO, G. et al. Uso da água em biótipos de azevém (Lolium multiflorum) em condição de competição. Planta Daninha, v. 25, n. 3, p. 449-455, 2007 b.

COUTINHO, C. F. B. et al. Pesticidas: mecanismo de ação, degradação e toxidez. R. Ecotoxicol. Meio Amb., v. 15, n. 1, p. $65-72,2005$

EBERHARDT, D. S. et al. Resistência de capim-arroz (Echinochloa crus-galli) ao herbicida quinclorac. In: CONGRESSO BRASILEIRO DA CIÊNCIA DAS PLANTAS DANINHAS, 22., 2000, Foz do Iguaçu. Resumos... Foz do Iguaçu: Sociedade Brasileira da Ciência das Plantas Daninhas, 2000. p. 512

\section{EMPRESA BRASILEIRA DE PESQUISA}

AGROPECUÁRIA - EMBRAPA. Centro Nacional de Pesquisa Agropecuária de Solos. Sistema brasileiro de classificação de solos. Rio de Janeiro: Embrapa Solos, 1999. $412 \mathrm{p}$

FERREIRA, E.A. et al. Potencial competitivo de biótipos de azevém (Lolium multiflorum). Planta Daninha, v. 26, n. 2, p. $261-269,2008$

GAZZIERO, D. L. P. et al. Resistência de amendoim-bravo aos herbicidas inibidores da enzima ALS. Planta Daninha, v. 16, n. 2 , p. $117-125,1998$.

GAZZIERO, D. L. P.; BRIGHENTI, A. M.; VOLL, E. Resistência cruzada da losna-branca (Parthenium hysterophorus) aos herbicidas inibidores da enzima acetolactato sintase. Planta Daninha, v. 24, n. 1, p. 157 $162,2006$.

GAZZIERO, D. L. P.; ADEGAS, F.; VOLL, E. Rotação obrigatória. Caderno Técnico Cultivar-Fitossanidade, n. 98, p. 9-10, 2007.

GELMINI, G. A. et al. Resistência de Bidens pilosa aos herbicidas inibidores da enzima acetolactato sintase utilizados na cultura da soja. Planta Daninha, v. 20, n. 2, p. $319-325,2002$

Planta Daninha, Viçosa-MG, v. 26, n. 2, p. 419-427, 2008
HEAP, I. The international survey of resistant weeds Disponible: $<\mathrm{http}$ ://www.weedscience.com $>$. Acesso em: 20 july 2007

KISSMANN, K. G.; GROTH, D. Plantas infestantes e nocivas. 2.ed. São Paulo: BASF, 1997. 825 p. Tomo I.

KISSMANN, K. G. Resistência de plantas daninhas a herbicidas. Disponível em: $<$ http://www.hrac-br.com.br $>$. Acesso em: 3 julho de 2000.

MEROTTO JR., A. et al. Resistência de Echinochloa sp. à quinclorac. In: CONGRESSO BRASILEIRO DA CIÊNCIA DAS PLANTAS DANINHAS, 22., 2000, Foz do Iguaçu. Resumos... Foz do Iguaçu: Sociedade Brasileira da Ciência das Plantas Daninhas, 2000. p. 513

MONQUERO, P. A.; CHRISTOFFOLETI, P. J.; DIAS, C T. S. Resistência de plantas daninhas aos herbicidas inibidores da ALS na cultura da soja. Planta Daninha, v. 18, n. 3 , p. $419-425,2000$.

MONQUERO, P. A. Biologia, manejo e caracterização bioquímica e genética de biótipos resistentes aos herbicidas inibidores da acetolactato sintase. Sci. Agríc., v. 60, n. 3, p. $495-503,2003$

NEVE, P.; POWLES, S. High survival frequencies at low herbicide use rates in populations of Lolium rigidum result in rapid evolution of herbicide resistance. Heredity, v. 85, n. 6 , p. $485-492,2005$

NOLDIN, J. A. et al. Sagitária resistente a herbicidas inibidores da enzima ALS. In: CONGRESSO BRASILEIRO DA CIÊNCIA DAS PLANTAS DANINHAS, 22., 2000, Foz do Iguaçu. Resumos... Foz do Iguaçu: Sociedade Brasileira da Ciência das Plantas Daninhas, 2000. p. 514.

NOLDIN, J. A.; EBERHARDT, D. S. Alternativas de controle químico de sagitária resistente aos herbicidas inibidores da ALS. In: CONGRESSO BRASILEIRO DE ARROZ IRRIGADO, 2.; REUNIÃO DA CULTURA DO ARROZ IRRIGADO, 24., 2001, Porto Alegre. Anais... Porto Alegre: IRGA, 2001. p. 574-578

NOLDIN, J. A.; EBERHARDT, D. S.; RAMPELOTTI, F. T. Cyperus difformis L. resistente a herbicidas inibidores da ALS em Santa Catarina. In: CONGRESSO BRASILEIRO DA CIÊNCIA DAS PLANTAS DANINHAS, 23., 2002, Gramado. Resumos... Londrina: SBCPD/Embrapa Clima Temperado, 2002. p. 198.

PINTO, J. J. O. et al. Resistência de picão-preto encontrada em lavoura de soja na metade sul do Rio Grande do Sul.

R. Bras. Herbic., v. 6, n. 2, p. 37-44, 2006

SAARI, L. L.; COTTERMAN, J. C.; THILL, D. C. Resistance to acetolactate synthase inhibiting herbicides. In: POWLES, S. B.; HOLTUR, J. A. M. Herbicide resistance in plants: biology and biochemistry. Boca Raton: Lewis, 1994. p. 83-139. 
SIGMAPLOT - Exact Graphy for Exact Science. Version 8.0, 1999

SOCIEDADE SUL-BRASILEIRA DE ARROZ IRRIGADO SOSBAI. Arroz irrigado: Recomendações técnicas da pesquisa para o Sul do Brasil. Santa Maria: Universidade Federal de Santa Maria, 2005. 159 p.

TRANEL, P. J.; WRIGHT, T. R. Resistance of weeds to ALS-inhibiting herbicides: What have we learned? Weed Sci., v. 50, n. 6, p. 700-712, 2002.

TREZZI, M. M. et al. Alternativas de controle químico para manejar biótipos de Euphorbia heterophylla com resistência simultânea a inibidores da ALS e da PROTOX. In: CONGRESSO BRASILEIRO DA CIÊNCIA DAS PLANTAS DANINHAS, 24., 2004, São Pedro. Anais... Londrina: Sociedade Brasileira da Ciência das Plantas Daninhas, 2004. CD-ROOM.
VARGAS, L. et al. Alteração das características biológicas dos biótipos de azevém (Lolium multiflorum) ocasionada pela resistência ao herbicida glyphosate. Planta Daninha, v. 23, n. 1, p. $153-160,2005$.

VARGAS, L. et al. Buva (Conyza bonariensis) resistente ao glyphosate na região Sul do Brasil. Planta Daninha, v. 25, n. 3 , p. $573-578,2007 \mathrm{a}$.

VARGAS, L.; MORAES, R. M. A.; BERTO, C. M. Herança da resistência de azevém (Lolium multiflorum) ao glyphosate. Planta Daninha, v. 25, n. 3, p. 567-571, 2007b.

VIDAL, R. A.; MEROTTO Jr., A. Resistência de amendoimbravo aos herbicidas inibidores da enzima acetolactato sintase. Planta Daninha, v. 17, n. 3, p. 367-373, 1999

VIDAL, R. A. Ação dos herbicidas. Porto Alegre: Universidade Federal do Rio Grande do Sul, 2002. 89 p. 